\title{
A Retrospective Assessment of Four Antigen Assays for the Detection of Invasive Candidiasis Among High-Risk Hospitalized Patients
}

\author{
Barbara Hartl • Iris Zeller • Angelika Manhart • Brigitte Selitsch • \\ Cornelia Lass-Flörl $\cdot$ Birgit Willinger (B)
}

Received: 29 August 2017/ Accepted: 15 December 2017/Published online: 22 January 2018

(C) The Author(s) 2018. This article is an open access publication

\begin{abstract}
Because of their high mortality rates and non-specific symptoms, invasive Candida infections pose a huge diagnostic and therapeutic challenge. In this study, we evaluated the three mannan antigen assays Platelia, Platelia Plus and Serion, and the (1-3)$\beta$-D-glucan assay Fungitell in a group of high-risk (hematological and surgical) patients. Test results of 305 patients hospitalized at the Vienna General Hospital and the University Hospital of Innsbruck were retrospectively analyzed. We assessed the test accuracy by means of descriptive statistics. Nine $(2.95 \%)$ patients were affected by invasive candidiasis (IC), and $25(8.2 \%)$ patients had a probable/possible infection. The majority of patients $(271 ; 88.9 \%)$ showed no signs of infection. The Platelia and Serion mannan assays had a low sensitivity $(65 \%$ and $52 \%$,
\end{abstract}

Electronic supplementary material The online version of this article (https://doi.org/10.1007/s11046-017-0238-1) contains supplementary material, which is available to authorized users.

B. Hartl · I. Zeller · A. Manhart · B. Selitsch .

B. Willinger $(\bowtie)$

Department of Laboratory Medicine, Division of Clinical Microbiology, Medical University of Vienna, Währinger Gürtel 18-20/5P, A-1090 Vienna, Austria

e-mail: birgit.willinger@meduniwien.ac.at

Present Address:

B. Hartl

Skånes universitetssjukhus, Getingevägen 4, 22241 Lund,

Sweden respectively), but high specificity ( $98 \%$ for both tests). The newer version of the Platelia assay, the Platelia Plus, had a higher sensitivity $(85 \%)$ but a lower specificity (89\%). The sensitivity of the Fungitell assay was high (100\%), while its specificity was low $(58 \%)$. The positive predictive values were 0.48 for the Platelia and 0.41 for the Serion assay, 0.26 for the Platelia Plus and 0.09 for the Fungitell assay. Our limited, retrospective study suggests the efficacy of mannan assays as screening (Platelia Plus) and confirmatory (Serion) tests, while the Fungitell assay can be used to exclude invasive Candida infections.

Keywords Invasive candidiasis - Diagnosis · Antigen $\cdot$ Mannan $\cdot$ BDG $\cdot$ Fungitell

Present Address:

A. Manhart

Courant Institute of Mathematical Sciences, New York

University, 251 Mercer Street, New York, NY 10012, USA

C. Lass-Flörl

Division of Hygiene and Medical Microbiology, Medical

University of Innsbruck, Schöpfstrasse 41,

A-6020 Innsbruck, Austria 


\section{Introduction}

The early diagnosis of invasive candidiasis (IC) is crucial, but, due to non-specific symptoms and a lack of rapid, reliable diagnostic procedures, very challenging [1-3]. Blood culture is considered the "gold standard" for the detection of IC, even though its sensitivity only lies between 50-75\% [4-6]. Different assays based on the detection of fungal cell wall antigens such as mannan and (1-3)- $\beta$-D-glucan (BDG) seem to be promising tools for the fast and sensitive detection of IC [7, 8]. Mannan assays are Candidaspecific, while BDG assays are able to detect a broad range of fungal species. The Platelia Candida Antigen Assay (Bio-Rad Laboratories, Marnes-la-Coquette, France) was evaluated in several studies showing sensitivities and specificities from 29 to $100 \%$ and 61 to $100 \%$, respectively [9-12]. According to the European Society of Clinical Microbiology and Infectious Diseases [13], this assay is suitable for the exclusion of IC. The Serion ELISA Antigen Candida Assay (Serion GmbH, Würzburg, Germany) has been scarcely discussed in the literature $[14,15]$ so far. With observed sensitivities and specificities between $47-78 \%$ and $70-100 \%$, respectively [9, 16-18], BDG assays are recommended by the European Organization for Research and Treatment of Cancer/ Invasive Fungal Infections (EORTC)/Mycoses Study Group (MSG) as suitable tool for the diagnosis of probable invasive fungal infections [19].

We evaluated the diagnostic performance of the Serion assay, the Platelia assay, the newer Platelia Candida Antigen Plus (Bio-Rad Laboratories, Marnes-la-Coquette, France) and the most common BDG assay (Fungitell; Associates of Cape Cod, Inc., MA, UA), by retrospectively analyzing test results of a cohort of hematological and surgical patients.

\section{Materials and Methods}

Blood samples of 305 hospitalized patients were collected at the Vienna General Hospital and the University Hospital of Innsbruck and tested with Platelia, Serion and Fungitell. In addition, 289 out of these patients were also tested with the Platelia Plus assay. The study included surgical intensive care patients as well as patients with leukemia and neutropenia of at least 14 days. Based on information from medical records and histopathological, radiological and microbiological findings, the patients were classified into three risk groups (proven IC, possible/ probable IC and no IC) according to the EORTC/MSG criteria. The limited access to some medical findings did not allow further differentiation between possible and probable IC. As our study was designed as retrospective analysis, the test results did not influence treatment decisions and thus did not affect the therapeutic outcomes.

\section{Statistics}

Test accuracy was assessed using descriptive statistics and calculating sensitivity, specificity, positive predictive value (PPV) and NPV. As multiple testing was not performed in all patients, the assays results were evaluated per sample and not per patient.

\section{Results}

Two hundred and five (67.2\%) out of 305 tested patients had been hospitalized at the University Hospital of Vienna, $100(32.7 \%)$ at the University Hospital of Innsbruck. In total, 189 (62.0\%) patients were men and $116(38.0 \%)$ women. The patients' ages ranged from 7 to 94 years (median 59 years).

Nine (3\%) out of 305 patients showed evidence of Candida species in samples from sterile sites at least once in close temporal relation ( \pm 7 days) to the date of antigen testing and were therefore regarded as patients with proven IC. According to the EORTC/ MSG criteria and in the context of other diagnostic findings and clinical symptoms, $25(8.2 \%)$ patients were assigned to the group of possible/probable IC, whereas $271(88.9 \%)$ patients showed no signs of IC. All in all, 824 blood samples were tested with the Platelia, 355 with the Platelia Plus, 848 with the Serion and 381 with the Fungitell assay (Fig. 1). Supplemental Table 1 summarizes inconclusive test outcomes.

\section{Patients with Proven IC}

The majority of patients $(7 / 9=77.8 \%)$ with proven IC were surgical patients, one patient had leukemia, while details regarding the underlying disease of another patient were not accessible for the analysis. As shown in Table 1, 5 out of $9(55.6 \%)$ infected patients 
showed positive results with the Platelia and the Platelia Plus assay, while samples from 4 (44.5\%) patients were positive upon testing with the Serion assay. The Fungitell assay was only conducted on samples from 6 patients and yielded a positive result in all cases, even though 1 out of 2 test results for a patient with confirmed $C$. lusitaniae sepsis was inconclusive. IC was successfully detected in 4 of the 9 patients by all four antigen assays. When the analysis was based on individual samples rather than patients, the Platelia and Serion assays showed detection rates of $61.90 \%$ for the Platelia and $50 \%$ for the Serion assay. The Platelia Plus $(84.62 \%)$ and the Fungitell (92.31\%) exhibited higher detection rates (Table 1). Patients were infected with C. albicans (5/ $9=55.5 \%)$, C. glabrata $(2 / 9=22.2 \%)$, C. parapsilosis $(1 / 9=11.1 \%)$ and $C$. lusitaniae (1/ $9=11.1 \%)$. C. albicans was detected in $7 / 13$ (53.9\%) samples with the Platelia, in $3 / 5(60 \%)$ with the Platelia Plus and $7 / 15$ (46.7\%) samples with the Serion assay, while detection rates for $C$. glabrata were $4 / 5(80 \%)$ with the Platelia, 6/6 (100\%) with the Platelia Plus and $3 / 6(50 \%)$ with the Serion antigen assay. The Fungitell detected $C$. albicans and $C$. glabrata in $100 \%$ of the samples from patients with proven IC. C. lusitaniae was detected in $2 / 2$ samples with the Platelia, Platelia Plus and the Serion assay, while Fungitell gave an inconclusive result in 1 out of 2 tests. In our study, only 1 patient was affected by $C$. parapsilosis and remained undetected by both mannan assays used; the BDG assay was not performed on the sample submitted from this patient within the \pm 7 day window (Table 2).

\section{Sensitivity, Specificity, PPV, NPV}

Samples that yielded in inconclusive results were excluded from further analysis. We used 2 different approaches to calculate sensitivity, specificity, PPV and NPV. First, we only included samples from patients with proven IC that were obtained \pm 7 days of the definite diagnosis as well as samples from patients without IC in our analysis. Additionally, we calculated these parameters when samples from patients with possible/probable IC were included in the group of proven IC patients. The false-positive as well as the false-negative rates were quite similar among the Platelia and Serion assays, whereas no false-negative results but a high rate of false positives were observed upon Fungitell testing in patients with proven IC. Also the Platelia Plus assay showed a considerably higher rate of false-positive results (Table 3).

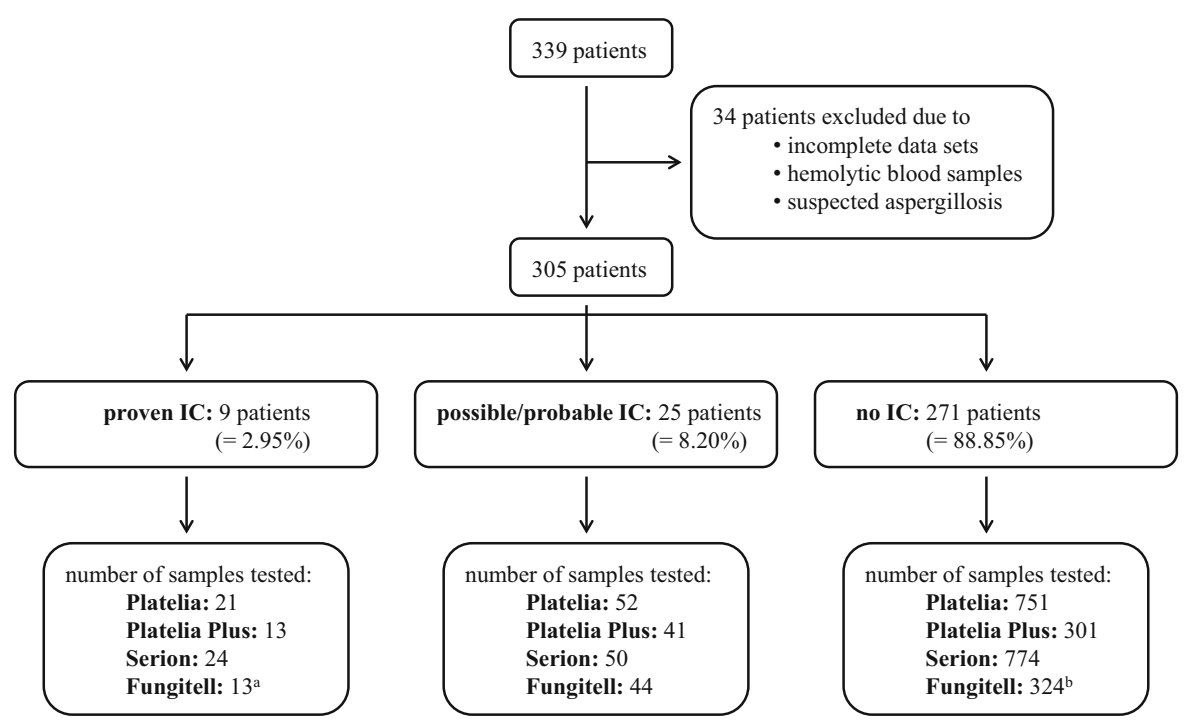

Fig. 1 Number of samples tested with Platelia, Platelia Plus, Serion and Fungitell among the three different patient groups. ${ }^{\text {a }}$ Only samples from 6 of the patients with proven IC were tested with Fungitell in close proximity to the time of IC diagnosis.

\footnotetext{
${ }^{\mathrm{b}}$ Samples from the 3 other patients that were only tested outside of the required time frame of \pm 7 days were added to the no IC group (274 patients)
} 
Table 1 Patients with proven IC

\begin{tabular}{|c|c|c|c|c|c|c|c|c|}
\hline \multirow[t]{2}{*}{ Patient } & \multirow[t]{2}{*}{ Diagnosis } & \multirow[t]{2}{*}{ Blood culture } & \multirow[t]{2}{*}{ Other results } & \multirow[t]{2}{*}{$\begin{array}{l}\text { Antifungal } \\
\text { treatment }\end{array}$} & \multicolumn{4}{|c|}{$\begin{array}{l}\text { positive results/samples tested } \pm 7 \text { days of } \\
\text { diagnosis }\end{array}$} \\
\hline & & & & & $\begin{array}{l}\text { Platelia } \\
13 / 21 \\
(61.90 \%)\end{array}$ & $\begin{array}{l}\text { Platelia } \\
\text { Plus 11/13 } \\
(84.62 \%)\end{array}$ & $\begin{array}{l}\text { Serion } \\
12 / 24 \\
(50 \%)\end{array}$ & $\begin{array}{l}\text { Fungitell } \\
12 / 13 \\
(92.31 \%)\end{array}$ \\
\hline 1 & Candidemia & C. albicans & - & Yes & $0 / 2$ & - & $0 / 3$ & - \\
\hline 2 & Candidemia & C. parapsilosis & - & Yes & $0 / 1$ & - & $0 / 1$ & - \\
\hline 3 & Deep organ candidiasis & - & $\begin{array}{l}\text { Pleural aspirate: } \\
\text { C. glabrata }\end{array}$ & Yes & $3 / 3$ & $3 / 3$ & $3 / 3$ & $3 / 3$ \\
\hline 4 & Candidemia & C. albicans & - & Yes & $0 / 1$ & & $0 / 1$ & - \\
\hline 5 & Candidemia & C. albicans & - & Yes & $3 / 3$ & $1 / 1$ & $3 / 3$ & $1 / 1$ \\
\hline 6 & Candidemia & C. albicans & PCR: C. albicans & Yes & $4 / 6$ & $2 / 2$ & $4 / 6$ & $2 / 2$ \\
\hline 7 & Endocarditis & - & $\begin{array}{l}\text { Histology + culture: } \\
\text { C. albicans }\end{array}$ & Unclear & $0 / 1^{\mathrm{b}}$ & $0 / 2^{\mathrm{b}}$ & $0 / 2^{\mathrm{a}}$ & $2 / 2$ \\
\hline 8 & Candidemia & - & PCR: C. glabrata & Yes & $1 / 2^{\mathrm{a}, \mathrm{b}}$ & $3 / 3^{\mathrm{b}}$ & $0 / 3$ & $3 / 3$ \\
\hline 9 & Candidemia & C. lusitaniae & BAL: C. lusitaniae & Yes & $2 / 2$ & $2 / 2$ & $2 / 2$ & $1 / 2^{\mathrm{a}}$ \\
\hline
\end{tabular}

${ }^{\mathrm{a}} 1$ sample yielded in an inconclusive result

${ }^{b} 1$ serum sample obtained was only tested with the Platelia Plus assay

Table 2 Detection rates for different Candida species in patients with proven IC

\begin{tabular}{lllll}
\hline & \multicolumn{4}{l}{ Positive results/samples tested \pm 7 days of diagnosis } \\
\cline { 2 - 5 } & C. albicans & C. glabrata & C. parapsilosis & C. lusitaniae \\
\hline Platelia $(n=21)$ & $7 / 13(53.85 \%)$ & $4 / 5(80 \%)$ & $0 / 1(0 \%)$ & $2 / 2(100 \%)$ \\
Platelia Plus $(n=13)$ & $3 / 5(60 \%)$ & $6 / 6(100 \%)$ & - & $2 / 2(100 \%)$ \\
Serion $(n=24)$ & $7 / 15(46.67 \%)$ & $3 / 6(50 \%)$ & $0 / 1(0 \%)$ & $2 / 2(100 \%)$ \\
Fungitell $(n=13)$ & $5 / 5(100 \%)$ & $6 / 6(100 \%)$ & - & $1 / 2(50 \%)$ \\
\hline
\end{tabular}

\section{Colonization}

Apart from the 9 infected patients, 31 (10.4\%) of the remaining 296 patients showed signs of colonization at the time of antigen testing. Among these colonized patients, 7 (22.6\%) gave false-positive results with the Platelia assay, $5(16.1 \%)$ with the Serion assay and 18 (58.1\%) with the Fungitell. The numbers of false positives among the group of non-colonized patients were $3(1.1 \%)$ with the Platelia assay, $5(1.9 \%)$ with the Serion assay and $72(27.2 \%)$ with the Fungitell.

\section{Discussion}

The major benefits of antigen testing are the short time to result and its cost-effectiveness. However, inconsistent observations regarding the test accuracies were reported in previous studies. This might be due to the heterogeneity of the available studies and the low prevalence of IC, since small numbers of positive samples make it difficult to draw conclusions of statistical significance. Among intensive care patients, for example, the prevalence was reported to only lie between 0.5 and $1 \%$ [20]. In our study, 9 out of 305 patients were classified as patients with "proven IC," which corresponds to a prevalence of $2.95 \%$ (Fig. 1).

For the Platelia assay, our study detected a sensitivity of $65 \%$, (41\% when possible/probable cases were included) and a specificity of $98 \%$ (Table 3). In a meta-analysis conducted by Mikulska et al. [11], an overall sensitivity of $58 \%$ and specificity of $93 \%$ were reported. We tested samples from 289 out of 305 patients also with the newer version of the Platelia 
Table 3 Test characteristics of the four antigen assays

\begin{tabular}{|c|c|c|c|c|c|c|c|c|}
\hline & \multicolumn{2}{|l|}{ Platelia } & \multicolumn{2}{|l|}{ Platelia plus } & \multicolumn{2}{|l|}{ Serion } & \multicolumn{2}{|l|}{ Fungitell } \\
\hline & Proven IC & $\begin{array}{l}\text { Proven, } \\
\text { probable or } \\
\text { possible IC }\end{array}$ & Proven IC & $\begin{array}{l}\text { Proven, } \\
\text { probable or } \\
\text { possible IC }\end{array}$ & Proven IC & $\begin{array}{l}\text { Proven, } \\
\text { probable or } \\
\text { possible IC }\end{array}$ & Proven IC & $\begin{array}{l}\text { Proven, } \\
\text { probable or } \\
\text { possible IC }\end{array}$ \\
\hline True positives & 13 & 29 & 11 & 20 & 12 & 26 & 12 & 34 \\
\hline True negatives & 709 & 709 & 259 & 259 & 710 & 710 & 170 & 170 \\
\hline $\begin{array}{l}\text { False negatives } \\
\quad \text { (false-negative rate) }\end{array}$ & $7(35 \%)$ & $41(58.5 \%)$ & $2(15.4 \%)$ & $31(60.8 \%)$ & $11(47.8 \%)$ & $44(62.9 \%)$ & $0(0 \%)$ & $17(33.3 \%)$ \\
\hline $\begin{array}{l}\text { False positives (false- } \\
\text { positive rate) }\end{array}$ & $14(1.9 \%)$ & $14(1.9 \%)$ & $31(10.7 \%)$ & $31(10.7 \%)$ & $17(2.3 \%)$ & $17(2.3 \%)$ & $123(42 \%)$ & $123(42 \%)$ \\
\hline Total & 743 & 793 & 303 & 341 & 750 & 797 & 305 & 344 \\
\hline Sensitivity & 0.65 & 0.41 & 0.85 & 0.39 & 0.52 & 0.37 & 1 & 0.67 \\
\hline Specificity & 0.98 & 0.98 & 0.89 & 0.89 & 0.98 & 0.98 & 0.58 & 0.58 \\
\hline PPV & 0.48 & 0.67 & 0.26 & 0.39 & 0.41 & 0.60 & 0.09 & 0.22 \\
\hline NPV & 0.99 & 0.95 & 0.99 & 0.89 & 0.98 & 0.94 & 1 & 0.91 \\
\hline
\end{tabular}

assay, the Platelia Candida Antigen Plus assay. This assay-which today is the only available Platelia Candida Antigen assay-was advertized to have a lower limit of detection compared to its predecessor. Lunel et al. [21] compared both tests and observed a modest increase in sensitivity, while the specificity was reduced by half due to a high number of falsepositive results in patients with superficial candidiasis. We were able to detect an increase in sensitivity to $85 \%$, while the decrease in specificity $(89 \%)$ was less prominent. The number of false-positive tests increased from 14 to 31 with Platelia Plus, whereas the number of false-negative results decreased from 7 to 2 .

The Serion assay showed a sensitivity of 52\% (37\% if possible/probable cases were included) and a specificity of $98 \%$ in our study. Lunel et al. [15] observed a sensitivity of $70 \%$ and specificity of $80 \%$ in patients with neutropenia lasting for less than 15 days, while in patients with prolonged neutropenia the sensitivity decreased to $46 \%$ and the specificity increased to $100 \%$. A sensitivity of $77 \%$ and specificity of $51 \%$ was reported by Chumpitazi et al. [14].

Both mannan tests gave false-negative results for patient 2, a patient diagnosed with $C$. parapsilosis candidemia. This might be due to the fact that the antibodies used only have weak reactivity for the antigens from $C$. parapsilosis and C. krusei as was shown by Rimek et al. [22] for the Platelia assay.
Sendid et al. [23] also observed poor detection of these species, and Yera at al. [24] reported detection rates $44 \%$ for C. krusei and C. parapsilosis with the Platelia assay.

Since time to detection is a very important factor in the diagnosis of invasive infections, we examined the applicability of antigen tests for the early detection of IC. Several studies suggest that antigen testing is superior to culture in terms of time to diagnosis [11] 26]. Even though only results obtained \pm 7 days of the definite (cultural or molecular) diagnosis of IC were included in the analysis of test quality parameters, results obtained outside of this 7 day window were reviewed. In 5 out of the 9 patients with proven IC, antigen assays gave positive results several days before culture positivity. All mannan assays as well as the Fungitell assay gave positive results 21 days before the culture results were available for patient 3 (C. glabrata was identified in the patient's pleural aspirate). However, at least 2 of these patients (patients 3 and 5) were also colonized by Candida, and it is not possible to evaluate whether the antigen assays detected the colonization or the infection.

The impact of fungal colonization on false-positive results and the low specificity remains unclear $[10,25]$. Nichterlein et al. [26] performed an animal study in which mice were infected with $C$. albicans systemically or gastrointestinally. The ability to differentiate between disseminated infection and mere 
colonization was examined for commercial mannan and BDG assays. Mice without detectable dissemination remained negative in the BDG assay but showed positive or intermediate results in the mannan antigen assay. Due to a lack of data in our study, only a part of the patients colonized at the time of testing could be identified. The number of false-positive results in the group of 31 colonized patients was much higher than in the group of 265 non-colonized patients regardless of the type of assay used.

In summary, despite the large number of patients in our study the statistical power is limited due to the low prevalence of IC. Nevertheless, based on the high specificity and low number of false positives we consider the mannan tests qualified for the confirmation of IC. Due to the higher specificity, the Serion assay might be the better confirmatory test, while the Platelia Plus could be used as a screening test. Its high sensitivity and high NPV make the Fungitell assay a valuable tool for the exclusion of IC, as has already been recommended [13]. In accordance with Poissy et al. [25], we recommend the combined use of mannan and BDG assays. Furthermore, these methods should only be used in combination with other diagnostic methods and interpreted in the context of clinical symptoms. Future studies could include other means of detecting invasive Candida infections, such as a Candida albicans germ-tube antibody assay $[27,28]$, and should focus on the analysis of serial antigen testing instead of single antigen test results. Larger, prospective studies are needed in order to develop reliable guidelines for an efficient use of antigen assays in practice.

Acknowledgements Open access funding provided by Medical University of Vienna.

Funding information Parts of the study were supported by the "Jubiläumsfonds" of the Austrian National Bank, grant\# 13491 to Birgit Willinger.

\section{Compliance with Ethical Standards}

Conflict of interest The authors declare that they have no conflict of interest.

Ethical approval All procedures performed in studies involving human participants were in accordance with the ethical standards of the institutional and/or national research committee and with the 1964 Helsinki Declaration and its later amendments or comparable ethical standards.
Informed consent For this type of study, formal consent is not required.

Open Access This article is distributed under the terms of the Creative Commons Attribution 4.0 International License (http:// creativecommons.org/licenses/by/4.0/), which permits unrestricted use, distribution, and reproduction in any medium, provided you give appropriate credit to the original author(s) and the source, provide a link to the Creative Commons license, and indicate if changes were made.

\section{References}

1. Garey KW, Rege M, Pai MP, Mingo DE, Suda KJ, Turpin RS, Bearden DT. Time to initiation of fluconazole therapy impacts mortality in patients with candidemia: a multi-institutional study. Clin Infect Dis. 2006;43(1):25-31.

2. Ostrosky-Zeichner L. Invasive mycoses: diagnostic challenges. Am J Med. 2012;125(1 Suppl):S14-24.

3. Stevens DA. Diagnosis of fungal infections: current status. J Antimicrob Chemother. 2002;49(Suppl 1):11-9.

4. Arendrup MC, Bruun B, Christensen JJ, Fuursted K, Johansen HK, Kjaeldgaard P, Knudsen JD, Kristensen L, Moller J, Nielsen L, Rosenvinge FS, Roder B, Schonheyder HC, Thomsen MK, Truberg K. National surveillance of fungemia in Denmark (2004-2009). J Clin Microbiol. 2011;49(1):325-34.

5. Arendrup MC, Fuursted K, Gahrn-Hansen B, Schonheyder HC, Knudsen JD, Jensen IM, Bruun B, Christensen JJ, Johansen HK. Semi-national surveillance of fungaemia in Denmark 2004-2006: increasing incidence of fungaemia and numbers of isolates with reduced azole susceptibility. Clin Microbiol Infect. 2008;14(5):487-94.

6. Kurzai O. Human Fungal Pathogens. Berlin: Springer; 2013.

7. Willinger B. Laboratory diagnosis and therapy of invasive fungal infections. Curr Drug Targets. 2006;7(4):513-22.

8. Lahmer T, Held J, Rasch S, Schnappauf C, Beitz A, Schmid RM, Huber W. Usage of 1,3-beta-D-Glucan for Early Detection of Invasive Mycoses and Outcome Parameter in Immunocompromised Critically III Patients. Mycopathologia. 2016;181(11-12):815-21.

9. Alam FF, Mustafa AS, Khan ZU. Comparative evaluation of (1, 3)-beta-D-glucan, mannan and anti-mannan antibodies, and Candida species-specific snPCR in patients with candidemia. BMC Infect Dis. 2007;7:103.

10. Ellis M, Al-Ramadi B, Bernsen R, Kristensen J, Alizadeh H, Hedstrom U. Prospective evaluation of mannan and antimannan antibodies for diagnosis of invasive Candida infections in patients with neutropenic fever. J Med Microbiol. 2009;58(Pt 5):606-15.

11. Mikulska M, Calandra T, Sanguinetti M, Poulain D, Viscoli C, Third European Conference on Infections in Leukemia G (2010) The use of mannan antigen and anti-mannan antibodies in the diagnosis of invasive candidiasis: recommendations from the Third European Conference on Infections in Leukemia. Crit Care. 14 (6):R222. 
12. Prella M, Bille J, Pugnale M, Duvoisin B, Cavassini M, Calandra T, Marchetti O. Early diagnosis of invasive candidiasis with mannan antigenemia and antimannan antibodies. Diagn Microbiol Infect Dis. 2005;51(2):95-101.

13. Cuenca-Estrella M, Verweij PE, Arendrup MC, ArikanAkdagli S, Bille J, Donnelly JP, Jensen HE, Lass-Florl C, Richardson MD, Akova M, Bassetti M, Calandra T, Castagnola E, Cornely OA, Garbino J, Groll AH, Herbrecht R, Hope WW, Kullberg BJ, Lortholary O, Meersseman W, Petrikkos G, Roilides E, Viscoli C, Ullmann AJ, Group EFIS (2012) ESCMID* guideline for the diagnosis and management of Candida diseases 2012: diagnostic procedures. Clin Microbiol Infect. 18 Suppl 7:9-18.

14. Chumpitazi BF, Lebeau B, Faure-Cognet O, Hamidfar-Roy R, Timsit JF, Pavese P, Thiebaut-Bertrand A, Quesada JL, Pelloux H, Pinel C. Characteristic and clinical relevance of Candida mannan test in the diagnosis of probable invasive candidiasis. Med Mycol. 2014;52(5):462-71.

15. Lunel FM, Mennink-Kersten MA, Ruegebrink D, van der Lee HA, Donnelly JP, Blijlevens NM, Verweij PE. Value of Candida serum markers in patients with invasive candidiasis after myeloablative chemotherapy. Diagn Microbiol Infect Dis. 2009;64(4):408-15.

16. Obayashi T, Negishi K, Suzuki T, Funata N. Reappraisal of the serum $(1->3)$-beta-D-glucan assay for the diagnosis of invasive fungal infections-a study based on autopsy cases from 6 years. Clin Infect Dis. 2008;46(12):1864-70.

17. Ostrosky-Zeichner L, Alexander BD, Kett DH, Vazquez J, Pappas PG, Saeki F, Ketchum PA, Wingard J, Schiff R, Tamura H, Finkelman MA, Rex JH. Multicenter clinical evaluation of the $(1->3)$ beta-D-glucan assay as an aid to diagnosis of fungal infections in humans. Clin Infect Dis. 2005;41(5):654-9.

18. Persat F, Ranque S, Derouin F, Michel-Nguyen A, Picot S, Sulahian A. Contribution of the (1->3)-beta-D-glucan assay for diagnosis of invasive fungal infections. J Clin Microbiol. 2008;46(3):1009-13.

19. De Pauw B, Walsh TJ, Donnelly JP, Stevens DA, Edwards JE, Calandra T, Pappas PG, Maertens J, Lortholary O, Kauffman CA, Denning DW, Patterson TF, Maschmeyer G, Bille J, Dismukes WE, Herbrecht R, Hope WW, Kibbler CC, Kullberg BJ, Marr KA, Munoz P, Odds FC, Perfect JR, Restrepo A, Ruhnke M, Segal BH, Sobel JD, Sorrell TC, Viscoli C, Wingard JR, Zaoutis T, Bennett JE, European Organization for R, Treatment of Cancer/Invasive Fungal Infections Cooperative $\mathrm{G}$, National Institute of A, Infectious Diseases Mycoses Study Group Consensus G (2008) Revised definitions of invasive fungal disease from the European organization for research and treatment of cancer/ invasive fungal infections cooperative group and the national institute of allergy and infectious diseases mycoses study group (EORTC/MSG) consensus group. Clin Infect Dis. 46 (12):1813-1821.

20. Eggimann P, Bille J, Marchetti O. Diagnosis of invasive candidiasis in the ICU. Ann Intensive Care. 2011;1:37.

21. Lunel FM, Donnelly JP, van der Lee HA, Blijlevens NM, Verweij PE. Performance of the new Platelia Candida Plus assays for the diagnosis of invasive Candida infection in patients undergoing myeloablative therapy. Med Mycol. 2011;49(8):848-55.

22. Rimek D, Singh J, Kappe R. Cross-reactivity of the PLATELIA CANDIDA antigen detection enzyme immunoassay with fungal antigen extracts. $\mathrm{J}$ Clin Microbiol. 2003;41(7):3395-8.

23. Sendid B, Poirot JL, Tabouret M, Bonnin A, Caillot D, Camus D, Poulain D. Combined detection of mannanaemia and antimannan antibodies as a strategy for the diagnosis of systemic infection caused by pathogenic Candida species. J Med Microbiol. 2002;51(5):433-42.

24. Yera H, Sendid B, Francois N, Camus D, Poulain D. Contribution of serological tests and blood culture to the early diagnosis of systemic candidiasis. Eur J Clin Microbiol Infect Dis. 2001;20(12):864-70.

25. Poissy J, Sendid B, Damiens S, Ichi Ishibashi K, Francois N, Kauv M, Favory R, Mathieu D, Poulain D. Presence of Candida cell wall derived polysaccharides in the sera of intensive care unit patients: relation with candidaemia and Candida colonisation. Crit Care. 2014;18(3):R135.

26. Nichterlein T, Buchheidt D, Hein A, Becker KP, Mosbach $\mathrm{K}$, Kretschmar M. Comparison of glucan detection and galactomannan enzyme immunoassay in gastrointestinal and systemic murine candidiasis. Diagn Microbiol Infect Dis. 2003;46(2):103-8.

27. Leon C, Ruiz-Santana S, Saavedra P, Castro C, Ubeda A, Loza A, Martin-Mazuelos E, Blanco A, Jerez V, Ballus J, Alvarez-Rocha L, Utande-Vazquez A, Farinas O. Value of beta-D-glucan and Candida albicans germ tube antibody for discriminating between Candida colonization and invasive candidiasis in patients with severe abdominal conditions. Intensive Care Med. 2012;38(8):1315-25.

28. Parra-Sanchez M, Zakariya-Yousef Breval I, Castro Mendez C, Garcia-Rey S, Loza Vazquez A, Ubeda Iglesias A, Macias Guerrero D, Romero Mejias A, Leon Gil C, MartinMazuelos E, Group CTS (2017) Candida albicans germtube antibody: evaluation of a new automatic assay for diagnosing invasive candidiasis in ICU Patients. Mycopathologia. 182 (7-8):645-652. 